\title{
Observações Sobre a Trilha Sonora Teatral em Diálogos
}

\section{* Marcos Machado Chaves}

\section{Resumo}

O presente artigo dialoga com oito criadores de trilha sonora teatral que contribuíram com a cena de Porto Alegre, pontuando questões que seguem abertas na relação entre música e teatro. Recorte de dissertação do autor, as entrevistas foram realizadas no ano de 2010 e continuam atuais. Nas observações, um olhar às dificuldades que podemos encontrar, na proposição sonora para a cena, em processos de criação teatral; percalços reverberados por distintas experiências e um elo de ligação - a necessidade de ampliar conversações sobre o universo existente entre música e cena.

Palavras-chave: trilha sonora - entrevista processo de criação

\begin{abstract}
This paper discusses with eight theatrical soundtrack creators who contributed to the scene of Porto Alegre, scoring questions that follow open in the relationship between music and theater. Author's dissertation clipping, the interviews were conducted in 2010 and are current. On the observations, a look to the difficulties that we can find in sound proposition for the scene in the theatrical creation processes; they are reverberated by different experiences and a link - the need to expand talks on the existing universe between music and scene.
\end{abstract}

keywords: sound design - interview - creation

\footnotetext{
* Doutorando pelo Programa de Pós-graduação em Teatro pela Universidade do Estado de Santa Catarina (UDESC). Professor do Curso de Artes Cênicas da Universidade de Grande Dourados. E-mail: marcoschaves12@gmail.com
} 
Qual o melhor termo para nos referirmos às sonoridades propostas em um espetáculo teatral? Alguns criadores preferem trilha sonora, outros utilizam repertório, desenho, paisagem, música de cena, sonoplastia (com atribuições diversas), dentre outras possibilidades. Creio não haver resposta correta ou definitiva, é interessante que os criadores de cada montagem se apropriem de métodos e conceitos que definam sua especificidade e nomenclatura. Todavia, nos permitimos o uso de "trilha sonora teatral" por seu uso frequente no Brasil. No presente artigo, um recorte da dissertação de mestrado do autor, defendida em 2011 pelo Programa de Pós-Graduação em Artes Cênicas da Universidade Federal do Rio Grande do Sul; há observações que mantém-se em pauta. A comunicação traz o diálogo com oito artistas que trabalham (ou trabalharam) com música para teatro na capital gaúcha, através de entrevistas realizadas no ano de 2010 com Adolfo Almeida Jr¹. , Álvaro RosaCosta $^{2}$, Arthur de Faria ${ }^{3}$, Flávio Oliveira ${ }^{4}$, Gustavo Finkler ${ }^{5}$, Johann Alex de Souza ${ }^{6}$, Nico Nicolaiewsky ${ }^{7}$ e Rafael Ferrari ${ }^{8}$.

Acreditamos que uma pontuação pertinente a ressaltar em diálogos sobre trilha sonora no teatro, trata de sua aplicabilidade e eventuais dificuldades decorrente das escolhas estéticas do conjunto de criadores no processo de criação de um espetáculo teatral. Uma das maiores questões colocadas ao criador de trilha sonora é se ela será gravada ou executada ao vivo. Responde-se que, mesmo gravada, sempre será uma mescla com os sons do momento, pois as vozes dos atores e demais sons do ambiente compõe a sonoridade do espetáculo. Entretanto, quando se utiliza o termo trilha gravada, trata-se de parte dela: sons propostos como efeitos sonoros e músicas de cena compiladas em mídias.

A trilha sonora ao vivo é aquela em que todos os sons são realizados no momento da apresentação, inclusive efeitos sonoros e músicas cênicas. Os criadores de trilha tendem a preferir esta opção: "entre a acústica ou a gravada? Se eu posso optar eu prefiro a acústica, pra teatro eu prefiro a acústica" (NICOLAIEWSKY, 2010). Entretanto, os custos geralmente reduzem a frequência desta alternativa nos palcos: "a gravação é uma maneira de viabilizar as coisas, mas geralmente o ideal é que fosse a música executada ao vivo" (ALMEIDA, 2010).

Ao pensar o modo de execução, é pertinente comentar uma colocação de Pablo Iglesias Simón a respeito da origem do som, classificando-o como diegético ou extradiegético: "denominamos diegético a todo som que pertence e se origina dentro do mundo da ficção. Como tal, é escutado por todos personagens que participam da mesma” (SIMÓN, 2005, p.12, tradução nossa). O som extradiegético é "todo aquele que não pertence nem se origina no mundo da ficção. Como tal, unicamente é escutado pelos espectadores"10 (SIMÓN, 2005, p.14, tradução nossa).

Ao falar sobre a origem do som, relaciona-se com o espaço de apresentação. Sendo diegético ou extradiegético, de onde o som proposto procede? Se das caixas de som, elas podem estar dispostas de várias maneiras, de frente para o público, direcionada para a cena, colocadas atrás do público, nas laterais do espaço de apresentação, e demais possibilidades.

Dependendo da origem do som, temos que ver se a fala deverá ser amplificada ou não, se a música utiliza instrumentos musicais no espaço de apresentação ou se é executada por aparelhos eletrônicos, assim como pensar na fonte dos efeitos sonoros. Estas decisões levam às opções da trilha sonora ser ao vivo ou utilizar sons gravados.

A trilha sonora ao vivo se divide em duas alternativas: acústica ou amplificada. Na acústica, o som da voz e dos demais materiais sonoros não está ligado a equipamentos eletrônicos, utilizando sua forma em relação com o ambiente para a propagação. De instrumentos musicais acústicos, citam-se, como exemplo, o violão e o piano. Na amplificada, o som da voz é microfonado, os materiais sonoros estão ligados a equipamentos eletrônicos, todos conectados a caixas de som. De instrumentos musicais "plugados" a amplificadores, citam-se, a

\footnotetext{
$1 \quad$ Porto-alegrense, compositor, cria trilha sonora para teatro, profissionalmente, desde a década de 80.

Natural de Porto Alegre, o artista cria trilha sonora para teatro desde 1997.

Porto-alegrense, compositor, intérprete, arranjador, produtor e instrumentista. Cria trilha sonora para teatro há 30 anos.

Natural de Santa Maria-RS, é compositor. Cria trilha sonora para teatro há mais de 50 anos.

Nascido em Porto Alegre, músico, cria trilha sonora para teatro há 30 anos.

Natural Santa Maria-RS, músico, cria trilha sonora para teatro há 18 anos.

Natural de Porto Alegre, foi músico e ator. Criou trilha sonora para teatro por 34 anos. Faleceu no ano de 2014 nos deixando com muitas saudades por sua arte e generosidade.

Porto-alegrense, bandolinista, compositor, arranjador, produtor musical e professor. Trabalha com trilha sonora para teatro desde o ano de 2006.

Denominamos diegético a todo aquel sonido que pertenece y se origina dentro del mundo de la ficción. Como tal es escuchado por los personajes que participan de la misma.

10 Denominamos extradiegético a todo aquel sonido que no pertenece ni se origina en el mundo de la ficción. Como tal únicamente es escuchado por los espectadores.
} 
guitarra elétrica e o teclado.

O uso de microfones na encenação é uma opção que pode ser um revés, principalmente microfones headset que são presos à cabeça do ator (geralmente na orelha), salvo exceções onde as escolhas se justificam, sem comprometer a sonoridade com enormes diferenças de equalização e quebras entre o som amplificado e o som acústico.

\begin{abstract}
Atualmente, o uso indiscriminado de microfones no teatro em Buenos Aires parece estar provocando um efeito indesejado porque, apesar deles, muitas vezes resulta igualmente dificil escutar e entender o que se diz em cena. [...] Os microfones amplificam o som que recebem, de forma que amplificarão a intensidade da voz e, com ela, alterarão todos seus outros parâmetros acústicos. [...] Assim, ao expor suas vozes a microfones, os atores se veem obrigados a reduzir drasticamente a intensidade, a articulação das consoantes e, inclusive, a alterar o timbre das vogais. ${ }^{11}$ (DAVINI, 2010, p.166, tradução nossa)
\end{abstract}

Em qualquer alternativa estética e criativa pode-se mesclar a opção da execução sonora, ter a música com seus instrumentos musicais gravados com os atores cantando no palco sem microfonação, a voz dos atores equalizada através de microfones acompanhada por instrumentos de percussão sem captação amplificada: uma grande gama de possibilidades é encontrada em cada processo de criação.

A maior diferença entre a opção de trilha ao vivo para gravada trata de um assunto subjetivo, que alguns músicos descrevem por feeling. Porque, quando o material é gravado, geralmente o criador encontra-se dentro de um estúdio de som, executando-o com poucas intervenções do ambiente e sem contato com o espectador. Resulta em uma captação onde a ordenação dos sons fora feita em um determinado dia, com certa emoção. A mesma se perpetua e é reproduzida na apresentação teatral, que certamente compactua de outros sentimentos que aqueles no momento da gravação.

\begin{abstract}
Antigamente eu pensava assim: se tu botar um cara tocando nos bastidores ali, mas se ouvindo, é a mesma coisa que ter um cd, mas eu descobri que não, é diferente! Se tu botar uma cortina e o cara tiver tocando lá só se enxerga a silhueta na cortina é diferente de ter um cd, porque as pessoas estão vendo que tem um cara tocando ali atrás, mesmo que não se veja ele direito, que só veja um vulto, é diferente. (SOUZA, 2010)
\end{abstract}

Apesar da suposta rigidez de uma trilha gravada, essa também está sujeita a alterações no acontecimento teatral. Porque sua propagação sempre será diferente devido à quantidade de espectadores e intervenção dos sons ambiente. Todavia, em uma escala muito menor em comparação com o som executado ao vivo.

Não existem regras para iniciar um processo de criação de trilha. Existem necessidades do espetáculo teatral, e diversas possibilidades de trabalhar a sonoridade proposta para colaborar com o processo de uma montagem.

Existem momentos em que o criador de trilha se depara com situações inusitadas quando não há sintonia de comunicação com o diretor. Ele pode ter na cabeça uma ideia sobre o que quer, e não saber expressar o que imagina. O diretor, às vezes, não tem como colocar em palavras as melodias que ocorrem em sua mente, $\mathrm{e}$ busca expressar códigos para serem traduzidos, como relata Gustavo Finkler: "aconteceu de uma diretora me pedir uma música mais azul, por exemplo. Se é difícil explicar, imagina entender. Foi aí que eu tive uma iluminação. Eu disse a ela: me diz que sensação tu queres causar no público e de quantos segundos tu precisas" (FINKLER, 2010). Desta forma, o artista estabeleceu uma comunicação direta: referência por sensação e tempo de duração.

A comunicação entre a equipe pode ser uma dificuldade em um processo de criação: Arthur de Faria prefere que o diretor dê as coordenadas do processo de criação do espetáculo teatral. Relata, inclusive, o exemplo de um trabalho de criação de músicas para um programa de televisão, e embora possa ter muitas diferenças com relação à criação no teatro, há paralelos com um processo de encomendas de música para utilização em uma obra artística:

\footnotetext{
11 Actualmente, el uso indiscriminado de micrófonos en el teatro en Buenos Aires parece estar provocando un efecto indeseado ya que, a pesar de ellos, muchas veces resulta igualmente difícil escuchar y entender lo que se dice en escena. [...] Los micrófonos amplifican el sonido que reciben, de forma que amplificarán la intensidad de la voz y, con ella, alterarán todos sus otros parámetros acústicos. [...] Assí, al exponer sus voces a los micrófonos, los actores se ven obligados a reducir drásticamente la intensidad, la articulación de las consonantes e, inclusive, a alterar el timbre de las vocales.
} 
A única vez que eu me estressei com uma trilha, foi uma trilha pra uma série de programa de televisão em que o diretor me disse "faz o que tu quiser", e eu fiz o que eu quis. Ai quando o cara ouviu disse "não é isso", eu disse "bom, lamento, não é isso não, é isso, vai ser isso, já está pronto, tu me disse faz o que tu quiser, eu fiz o que eu quis, foi o que tu decidiu”. (FARIA, 2010)

Todavia, acreditamos que um dos problemas mais difíceis de resolver estejam conectados com a parte técnica, com a execução. O trabalho com sonoridades no teatro gera muitas questões sobre a disposição espacial dos meios de produção de som. Dúvidas a respeito do espaço de apresentação, como: em que local o grupo irá apresentar a montagem teatral? Será em um palco tradicional, italiano? Quais dimensões? De que são feitas as paredes do edifício teatral? Como estão dispostas as cadeiras da plateia? A apresentação será em um espaço não convencional? Vai ser ao ar livre? Na rua? Em que rua? Tais questões têm como eixo a propagação do som.

Os atores sabem naturalmente, por exemplo, que na capital gaúcha apresentar no Theatro São Pedro e na Sala Álvaro Moreyra (ambos os espaços contemplam diversas montagens teatrais por ano) é bem diferente. Nem é preciso falar ao ator sobre a projeção de voz dele em um espaço tradicional como o primeiro, onde cabem aproximadamente 700 espectadores, ou em um espaço mais intimista como o segundo que tem capacidade para 110 pessoas.

Diferenciar projeção vocal para apresentação de uma peça teatral em uma sala ou na rua está presente nestas questões. Há consciência por parte de muitos atores, acostumados com a prática, da intensidade que será necessária para enunciar um texto em diferentes locais.

Em sala, há outras questões importantes para a execução: os aparelhos eletrônicos. Dúvidas como a localização da cabine de som; se há equalizador; quantos canais possui a mesa de som; se possui aparelho reprodutor de mídias sonoras, e se está em boas condições; onde estão posicionadas as caixas de som, e se é possível alterá-las; se existem caixas de retorno, monitores para os atores. São perguntas que precisam de respostas quando um espetáculo teatral se prepara para a execução. Tais dúvidas se referem a uma parte das sonoridades propostas no processo de criação.

$\mathrm{Na}$ apresentação da obra teatral, esbarra-se em problemas como a falta de equipamentos adequados. Dificuldade essa que já vem dos ensaios, como relata Adolfo Almeida Jr.:

\footnotetext{
Não ter o equipamento de som quando é uma peça que precisa de sonorização, e dai não consegue ensaiar adequadamente, fica até o último dia com um gravadorzinho pequeno... Essas limitações assim tecnológicas de toda ordem que o teatro aqui enfrenta, um problema de quase um semi-amadorismo, vamos dizer, também porque não existe uma estrutura já pronta pra isso. Tu chegas nos teatros e não tem nada, só tem uma pessoa que cuida do teatro, então tens que estar trazendo tudo... Isso é um pouco triste de ver, o espetáculo perde dentro daquilo que foi imaginado como poderia ser, e dai sempre é montado um pouco mais precário, uma coisa meio frustrante desse ponto de vista do acabamento. (ALMEIDA, 2010)
}

Alguns destes problemas sobre equipamentos técnicos são possíveis de sanar ao se repensar, nos projetos de encenação, sobre o valor destinado à sonoridade do espetáculo teatral, para dar suporte a recursos (durante o processo de criação e nas apresentações) que necessitem de maior investimento financeiro, talvez o aluguel de equipamentos adequados.

Assim Gustavo Finkler discorre, a respeito da gravação em estúdio para execução da trilha gravada: “a diferença entre um estúdio bom e um não bom é tão grande, o trabalho se torna tão mais ágil, fácil, leve. Então fica aqui o meu pedido aos diretores: reservem uma cota razoável para a gravação da trilha. Irá fazer toda a diferença" (FINKLER, 2010). Uma parcela no orçamento não é garantia de bons resultados, mas respalda uma pesquisa sonora na montagem, agregando profissionais que possam viabilizar soluções para a apresentação da obra.

Uma pergunta feita aos entrevistados, "quais são as dificuldades que você costuma encontrar no trabalho com trilha sonora?”, gerou muitas respostas, com um viés de lamentações, mas não no sentido de reclamar apenas, e sim para apontar problemas no intuito de desvelar situações incômodas que podem, em trabalhos futuros, ser diferentes.

Flávio Oliveira, em sua entrevista, abarca situações comentadas pelos outros criadores de trilha e, de todos os entrevistados, demonstrou maior desconforto com as dificuldades encontradas. De modo que sua colocação resume alguns pontos citados por outros criadores. 
É difícil ensaiar com um aparelho de som precário, mas pior é observar tal precariedade no espaço de apresentação. Oliveira observa que "todos os teatros de Porto Alegre prejudicam qualquer tipo de sonoridade do palco, porque eles trazem sonoridade da rua, uns mais, uns menos, quer dizer, Porto Alegre carece de teatros que tenha vedação sonora" (OLIVEIRA, 2010).

A interferência sonora na obra teatral acontece em todas as apresentações. Entende-se por interferência algo ligado aos sons involuntários, ao acaso. Porém, a colocação de Oliveira é pertinente e questiona: não se poderia prever e diminuir alguns sons que interferem de forma externa ao teatro, e ter um espaço teatral com melhores condições acústicas?

Outro problema diagnosticado pelos criadores de trilha sonora são os aparelhos de som. Nas entrevistas encontram-se dois apontamentos sobre tal questão: aparelhos inadequados e falta de um profissional que domine o manuseio do mesmo, como diz Álvaro RosaCosta: “por isso eu acho que é tão importante um sonoplasta [operador de som], talvez seja meio a meio com o criador porque um mau sonoplasta acaba com a trilha, assim como um bom sonoplasta faz daquela trilha, um brilho a mais" (ROSACOSTA, 2010). O responsável por tais equipamentos no teatro é o técnico de som, o operador é encarregado de manuseá-los. Flávio Oliveira comenta que "os operadores de som são pessoas absolutamente despreparadas... E nós estamos vivendo em uma época em que os shows e apresentações, se tu botar um decibelímetro, tá acima daquilo que satura" (OLIVEIRA, 2010). O compositor, que trabalha há mais de 50 anos no ramo, deflagra o atual momento de uma execução de som: normalmente os profissionais de som que trabalham no teatro também desempenham sonorização de eventos, shows, formaturas. Constata-se que "botar som" para uma apresentação de grupo ou banda musical demanda potência do equipamento de som, e também qualidade, mas o enfoque está - infelizmente - na potência. No teatro, é necessária uma equalização pertinente com os sons criados. As fontes de produção de som, os alto-falantes, dependendo do trabalho precisam ser deslocadas para outras partes do espaço teatral. A mudança de local das caixas de som é parte do problema, pois é comum que se tenha aparelhos fixos com pouca margem para alterá-los de acordo com a necessidade da montagem.

No espetáculo $\mathrm{O}$ Avarento ${ }^{12}$, experiência do autor, combinou-se com a equipe que a execução da trilha proposta para a montagem, de efeitos sonoros e músicas gravadas, deveriam ser (a disposição dos alto-falantes) somente por trás dos atores no fundo do palco. Tal decisão faz parte da concepção, não é preciosismo do responsável pelas sonoridades. Nesta montagem os atores cantam em cena sem microfones, e a colocação das caixas de som ao fundo do palco serviria tanto de retorno para os artistas quanto para apreciação do público. A sensação que se propôs, foi misturar os instrumentos gravados com as vozes dos atores, fazendo a sonoridade chegar no público ao mesmo tempo, sem desviar o foco de produção de som da cena.

Esta concepção resultou em uma preocupação a mais, porque em todas as apresentações deslocam-se as caixas de som ou monitores para trás do palco, mas há lugares onde não é possível tal recurso. Seria interessante que o grupo investisse em um material que julgasse adequado e levasse junto com o cenário, mas aparelhos de som de qualidade necessitam de um investimento razoável. O grupo encontrou sua solução no trabalho com as possibilidades (aparatos técnicos existentes) em cada novo local de apresentação, e, se for o caso, alugar o equipamento para determinado edifício teatral. $\mathrm{O}$ aluguel de equipamentos sonoros geralmente é feito com profissionais de sonorização de eventos: voltamos a um círculo vicioso.

Vivemos hoje em uma época cuja tendência é vincular alta intensidade sonora como sinônimo de qualidade de som. Na rua ou em veículos automotivos, nos parece que quanto mais alto o volume do som, melhor. Esta cultura chega ao teatro com os profissionais responsáveis pelos equipamentos sonoros, acostumados com volumes altíssimos e, como diz Oliveira, tem dificuldades em dosar o som no ambiente: "é uma briga para eles saberem onde é que entra com pouco volume, onde é que cresce" (OLIVEIRA, 2010). O compositor é incisivo porque considera tal problema como crucial no teatro, cita que "qualquer pessoa acha que pode operar a música, e se eu entrar numa sala de cirurgia e quiser fazer uma microcirurgia oftalmológica pra retirar uma catarata, eu vou pra cadeia" (OLIVEIRA, 2010).

Oliveira enfatiza que qualquer pessoa é autorizada por um diretor, ou por um produtor, para operar um equipamento de som. A falta de conhecimento sonoro da produção do espetáculo é proporcional à dificuldade de resolver problemas que a execução da trilha carece em um espaço de apresentação.

\footnotetext{
12 Espetáculo do Grupo Farsa contemplado com o Prêmio Funarte de Teatro Myriam Muniz 2008 que integrou o projeto "Ās Três Batidas de Molière" da trupe gaúcha, com direção de Gilberto Fonseca, direção musical e criação de trilha sonora de Marcos Chaves, estreou em 2009 em Porto Alegre-RS.
} 
Então a outra dificuldade é que a acústica dos lugares ela exige que as caixas, ou que os aparelhos de reprodução sonora sejam colocados em determinados lugares. E é muito difícil que uma pessoa como eu, vamos dizer, que estou fazendo o som, a música, enfim, possa dialogar com quem vai colocar as caixas de som onde quer colocar, quer dizer, tu não tens o menor crédito, e ai eu acho que os diretores falham, com algumas exceções é claro, os diretores e os produtores falham. (OLIVEIRA, 2010)

Nesta entrevista, após um parecer vigoroso, o compositor conclui que estas considerações o deixam com sensações ruins: "eu falo um tanto emocionado, estressado, assim, porque parece que voltam as pendências. Existe muito descaso, desrespeito" (OLIVEIRA, 2010). De fato, isto nos faz pensar sobre o conceito que alguns envolvidos com a arte teatral possuem a respeito da sonoridade. Todos estes problemas fazem parte das relações humanas em uma equipe de trabalho, aliados à falta de recursos ou preparos adequados em uma montagem.

As maiores dificuldades encontradas são sobre a execução da trilha em relação com o espaço de apresentação e vinculadas à questão orçamentária, seja do espetáculo ou dos próprios edifícios teatrais com frágeis infraestruturas na questão tecnológica do som.

No teatro de rua também encontramos percalços na execução da trilha sonora, como podemos observar no relato de Johann Alex de Souza, ao perceber um problema com a peça já em andamento:

\footnotetext{
Então a coisa do teatro de rua é importante porque a gente viu que certas coisas não funcionam muito na rua em termos sonoros mesmo, em termos de música. Eu fiz a musica da "Saga de Canudos" que foi a peça anterior de rua do grupo Ói Nóis, e a gente colocou vários violões e os violões não aparecem na rua. Eu descobri, não sabia disso, que o violão não adianta, a não ser que tu coloques cinquenta violões, mas eram seis violões com corda de aço, os caras dando "palhetaço" e não se ouvia! Eu assisti várias vezes. Chegava na hora e não se ouvia, rebentava corda de tanto que os caras batiam forte. Então são pequenas coisas assim que a gente vai descobrindo. E dai tu vai descobrindo porque as pessoas gostam de usar mais gaita na rua, porque além da questão cênica tem a questão do volume, que são os instrumentos que aparecem mais. (SOUZA, 2010)
}

No teatro de rua, temos também a dificuldade de transportar o equipamento necessário, por isso o uso comum de gaitas: por sua intensidade sonora e peso do instrumento. Souza prefere a gaita de oito baixos ao acordeom pela facilidade de carregar. Instrumentos leves de percussão, ou um violino, combinam em vários fatores com um espetáculo teatral de rua.

Se buscássemos possibilidades "ideais" para a criação de trilha no espetáculo, recomendaríamos investimento financeiro para as questões musicais na obra teatral, e participação imersa do artista responsável pela interlocução musical na montagem.

\footnotetext{
O ideal é o processo onde o compositor está acompanhando toda a evolução da criação dos personagens do texto, da movimentação, do cenário, do figurino, onde ele é realmente uma parte integrante daquele trabalho, não é uma coisa a parte que ele faz na casa dele, só pensando com as ideias dele, tem uma série de coisas ali envolvidas, de várias pessoas, de vários profissionais. (FERRARI, 2010)
}

Se existem dificuldades na proposição musical para a cena, existe também a superação dos atores que, em apresentação, procuram não transparecer os percalços encontrados na montagem do espetáculo. Na sonoridade teatral há ainda a dificuldade pessoal dos atores em relação a um dos mais importantes materiais sonoros de uma encenação: a voz. As inquietações podem vir de insegurança derivada da quantidade de trabalhos vocais em cada montagem. Nas observações sobre trilha sonora, sobre as sonoridades presentes no teatro, desde as músicas ou efeitos propostos às interlocuções a partir dos atores, pensando na musicalidade do espetáculo, encontramos um alento nas palavras de Nico Nicolaiewsky - tudo passa pela experiência. Superemos eventuais dificuldades e resultemos em vivências pessoais dentro das atualizações musicais na arte teatral. 
dou, eu curto eles, na verdade, como uma questão musical. Como uma questão de, quer dizer, a questão musical que são, a entonação dele, se ele é mais grave, ele é mais agudo, os aceleramentos ou desaceleramentos, os tempos, o quanto eu posso aproximar do microfone e falar de uma outra forma, que é uma emissão bem diferente de uma outra, que é mais forte... Pra mim isso tudo, na verdade, é música que é tudo que a pessoa escuta, tudo o que passa pelo ouvido pra mim tá dentro da área da música. (NICOLAIEWSKY, 2010)

Ampliemos diálogos sobre trilha sonora teatral e sobre o universo existente entre música e cena. Teatro e música são artes que estão conectadas. Na contemporaneidade o som no teatro pode ser ponto de partida, elemento figurante, coadjuvante ou protagonista... Escolhamos conscientemente em debate contínuo e produtivo ao espetáculo teatral.

\section{Referências}

CAMARGO, Roberto Gill. A sonoplastia no teatro. Rio de Janeiro, Instituto Nacional de Artes Cênicas, 1986.

DAVINI, Silvia. Cartografías de la voz em el teatro contemporâneo: el caso de Buenos Aires a fines del siglo XX. Bernal: Universidad Nacional de Quilmes, 2007.

GUBERFAIN, Jane Celeste. Voz em cena - volume I. Rio de Janeiro: Editora Revinter, 2004.

KOWZAN, Tadeusz. “Os signos no teatro - Introdução à semiologia da arte do espetáculo”. In: GUINSBURG, J. (org). Semiologia do teatro. São Paulo: Perspectiva, 2003.

LEHMANN, Hans-Thies. Teatro pós-dramático. São Paulo: Cosac Naify, 2007.

SCHAFER, R. Murray. O ouvido pensante. São Paulo: Fundação Editora da UNESP, 1991.

SIMÓN, Pablo Iglesias. El diseñador de sonido: función y esquema de trabajo. España: Madrid, 2005.

TRAGTENBERG, Lívio. Música de cena. São Paulo: Perspectiva: FAPESP, 1999.

Entrevistas:

ALMEIDA JR., Adolfo. Entrevista concedida a Marcos Chaves - realizada na cafeteria da Usina do Gasômetro $3^{\mathrm{O}}$ andar, Porto Alegre: 19 jan. 2010.

FARIA, Arthur de. Entrevista concedida a Marcos Chaves - realizada na rádio Pop Rock, Porto Alegre: 15 jan. 2010.

FERRARI, Rafael. Entrevista concedida a Marcos Chaves - realizada na cafeteria da Casa de Cultura Mário Quintana - andar térreo, Porto Alegre: 26 mar. 2010.

FINKLER, Gustavo. Entrevista concedida a Marcos Chaves - realizada através de correspondência eletrônica, Porto Alegre: 05 fev. 2010.

NICOLAIEWSKY, Nico. Entrevista concedida a Marcos Chaves - realizada na casa do artista, Porto Alegre: 22 jan. 2010. 
OLIVEIRA, Flávio. Entrevista concedida a Marcos Chaves - realizada na casa do artista, Estância Velha: 05 abr. 2010.

ROSACOSTA, Álvaro. Entrevista concedida a Marcos Chaves - realizada na casa do artista, Porto Alegre: 14 jan. 2010.

SOUZA, Johann Alex de. Entrevista concedida a Marcos Chaves - realizada na Palavraria, Porto Alegre: o1 abr. 2010. 